\title{
Exploring Ethical Dilemma in Big Data Analytics: A Literature Review
}

\author{
Kelvin Tak Yiu Leung ${ }^{1}$, Antoś Dembicz ${ }^{2}$, Anne Stevenson ${ }^{3}$ \\ ${ }^{1}$ University of Information Technology and Management, Poland \\ ${ }^{2}$ University of Warsaw, Poland \\ ${ }^{3}$ Columbia Southern University, USA \\ Corresponding author: kelvinleung@alumni.polyu.edu.hk
}

\begin{abstract}
Big data analytics has remarkably transformed every sector of the world, including the Emergency Service sector, health sector, science, and space, as well as the business sector, in the way they manage and run their activities every day. Big data analytics has made it possible and easier for all of these sectors to predict future outcomes, make more adequate critical decisions, and take more effective actions respectively. It now gives businesses the power to obtain, access, and leverage customers' data, and even control their behaviors. Many sectors are leveraging big data in that respect, especially businesses. They are incorporating big data analytical tools to obtain consumers' data and access their personal information, such as their interests, behavioral pattern, ideas, security details, personal interactions, etc., which they store and leverage for their benefits. This information is obtained and accessed usually without the conscious knowledge and approval of their consumers.
\end{abstract}

This is the major factor that has raised ethical concerns in several leaders and experts about the extent of the personal information that can be accessed, as well as the safety and wellbeing of the common people who are unaware that their personal data is being saved, accessed with purpose. Another concern is about the freedom of individuals. With the new invented technologies and implementation of big data analytics, many of the businesses can technically control their users; what they want, need, and do, and thus, depriving them of the freedom to make decisions on their own. There is also another concern concerning the safety of the intellectual property of individuals and corporations. Big data analytics can lead to intellectual property infringement and theft, thereby denying people and organizations the right to consumers' data that they obtain and utilize for their benefit. 
While on one hand big data analytics produce great promises, on the other hand, it generates critical ethical in both security and privacy issues, which if left unaddressed may become significant barriers to the fulfillment of expected opportunities and longterm success of big data. In this paper, we discuss the ethical dilemmas in big data analytics.

KEYWORDS: Big data ethics, data management decision, business ethics

\section{INTRODUCTION}

Disruptive changes in technology, along with expectations of the society that are partly shaped by these changes, continue to generate significant ethical concerns. These include new questions about the extent of individual privacy, security, and awareness, and the proper role of intellectual property protection. Challengingly, the law affords no moral rule to balance the competing interests of individuals, industries, and society as a whole in the rapidly increasing age of Big Data. In the next few pages, we will discuss some of the ethical dilemmas.

\section{Privacy Concerns}

To business establishments, leaders, marketers, and analysts, big data could mean the key to a new age of business intelligence and personalized business service delivery. By employing big data analytics, businesses can obtain and visualize hidden patterns and meaningful insights from various internal and external data sources. Leveraging this knowledge, they can add intelligence to their processes, improve operational efficiency, gain competitive advantages, and boost sales.

Significantly, by accurately analyzing complex, heterogeneous, and large data sets, (i.e., data from companies' internal sources and the growing fast-flow of heterogeneous data available externally) business analysts can, among other things, optimize their marketing and advertising strategies, gain real-time insight into their customers' needs, usage, and buying patterns, and possibly identify emerging (product/market) trends early on. Many companies, especially online platforms (Internet and social media), retailers, and marketplaces (Amazon, etc), are already applying big data techniques to their vast databases of consumer purchase histories, transactional information and inventory data to;

i. Gain a better understanding of their customers.

ii. Provide current and potential customers with personalized products, services, and recommendations, and

iii. Predict changes and shift in demand.

With big data analytics, sales and marketing professionals can also leverage the mountain of data that customers create when using smart devices to access online services, when making online purchases with electronic cards, or when sharing their locations and private thoughts on social networks, to target the right consumer at the right time with the right message. 
But while the rise of big data creates huge opportunities for business leaders, organizations, and the society at large, it also raises important privacy issues. Big data has allowed businesses and analysts to generate and access consumers' data without the knowledge of and direct permission from the consumers, and are often put to unforeseen uses after they have been obtained. That does not only implicate privacy, it also leads to second-order harms, such as profiling, tracking, discrimination, exclusion, government surveillance, and loss of control.

Furthermore, it's also been observed that specific data-driven businesses in telecommunication giants and social platforms are beginning to sell their consumers' information to buyers looking to use those data to drive critical business decisions and boost sales. Although this information is said to be used only to drive more target marketing strategies and make critical business decisions, there is also a possibility of misuse of the information. That does not only deny consumers right over their personal information but also poses a threat to their security, thereby exposing them to potential harm.

These issues do not only create doubts about whether consumers' right to maintain control over data that they directly and indirectly disclose can be fully implemented, they also raise the question of whether individual control of personal data is an achievable goal in the context of big data. In the face of the complex life-cycle of personal data in big data, the consumers' right to individual access raises an important question: How can consumers' safety and rights to have access and control over all of their data be ensured at the infrastructural level?

Similar concerns have been expressed in the medical field, where the electronic storage and distribution of individuals' health data can potentially reveal information not only about the individuals but also about the people related to them. This was seen in a case that occurred in the United States, where the genome data of a diseased woman were publicly available, which rose objections from her family members. Though her information was subsequently removed, it caused worry for advocates of open access that privacy concerns might significantly slow the progress of Big Data research. Nevertheless, health data collected without personal information would still provide accurate research findings to understand exact occurrence time, temperature, age and gender that affecting our life in out-of-hospital cardiac arrest situation (Low et al., 2018).

Another ethical concern relative to the level of protection of consumers' privacy and the security of their data and interactions with others is the unsecured/unencrypted storage of data which leaves it unprotected, unsafe, and vulnerable to attack. Ultimately, individuals' data can be accessed and hijacked for negative intentions by unauthorized personnel, and that poses a huge threat to the safety, security, and general wellbeing of the individuals. A typical example where private data was accessed and misused is the case of Hilary Clinton, who was a co-runner for the position of the president in the United States in 2016, whose email was hacked into and used against her, according to various political analysts and individuals (Davis, 2018), that action caused her to lose in the presidential race

Governments' use of Big Data creates another privacy concern. It has been revealed in law enforcement agencies monitor the email and mobile communications of millions of their population, which might be the peak of big data analytics concerns. Consequently, some leading commentators argue that the approach 
violates privacy. Though some citizens seem to be bothered about the privacy violations, the official defense by the government tends to highlight that data gathering did not examine the substance of emails, private chats, and phone calls, but rather focused on more general metadata (CROMI, 2015).

Despite existing data privacy protection frameworks, which guarantee the right not to be subjected to such surveillance, big data analytics can expand governments' and businesses' ability to surveil private citizens, ultimately undermining individuals' right to privacy, anonymity, and free expression. Without consensus in the society on the extent of data retention and surveillance laws and their interplay with data protection laws, big data programs risk being negatively impacted, derailed, or even stopped by public backlash and legal challenges.

\section{Awareness Concern}

Awareness deals with what individuals know about big data analytics practices, such as how organizations analyze and utilize their data to drive critical decisions. An ethical dilemma generates when individuals lack awareness about why organizations use big data analytics and the processes involved in it (Newell \& Marabelli, 2015). Aspects of awareness that highlight ethical issues in big data analytics are, understanding the concept of big data analytics, understanding the rights regarding big data analytics, and understanding who holds the data and the purpose for which it's used. Unfortunately, the majority of the world is not aware of what big data analytics is, how it operates, and that their data and information is being utilized by several agencies and organizations. Organizations usually collect big data directly and indirectly without clear informed consent of their subjects, and often hide secondary uses of the data from individuals (Barocas \& Nissenbaum, 2014). This lack of awareness is the underlining factor that has created the greatest challenge to individuals' privacy, security, and freedom.

Many leaders and experts argue that individuals need to learn about big data analytics, how it operates, and how it influences their choices and behavior (Crawford \& Schultz, 2014). They also believe that, Individuals need to engage in public data literacy programs and recognize appropriate uses and consequences of big data analytics (Zuboff, 2015). That way, people can learn to better balance the personal costs and benefits of big data analytics (Newell \& Marabelli, 2015). Second, individuals need to be aware of laws and policies that exist to protect them from the potential negative consequences of big data analytics [e.g., the European General Data Protection Regulation (GDPR)]. Third, individuals should know the kind of data organizations collect about them, who owns and controls it, and about the third parties that might have access to it (Crawford \& Schultz, 2014; Markus, 2015). Individuals need to know about these practices since the analytics carried out on their data will ultimately influence their lives.

\section{Intellectual Property Concern}

Just like creativity and innovation, data is priceless. Creativity and innovation are termed intellectual properties and are protected by certain laws (copyrights/patent/trademark) against theft, false claim, and infringement. The intellectual property protection laws allow owners to have full rights over their creations and prevent them from being stolen, claimed, or compromised. 
Unfortunately, conventional data is not regarded as an intellectual property, and is not prospected by the law. That is because, according to law agencies, it does not meet the eligibility requirements for patent or copyright protection. This limitation affects the concept of data ownership. This means that individuals' data obtained, stored, and utilized by a particular entity can also be freely utilized by another entity, without restriction or charge. In that case, it's easy for individuals' data to be compromised and even misused. This remarkable challenge gives concern to data extractors, leaders, and agencies about the ownership and accountability of data, as well as the safety of individuals' information.

This, therefore, questions the accountability of data users, as well as suggests important changes to dominant legal constitutions and practices to support data ownership and protection.

\section{CONCLUSION}

Big Data is significantly endowed with a kind of novelty that is productive and empowering yet constraining and overbearing. With the burgeoning power of Big Data techniques and technologies, we can now make more accurate predictions and potentially better decisions in dealing with health epidemics, natural disasters, social unrest, as well as business marketing and sales. At the same time, however, one cannot fail to notice the ethical challenges and dilemmas it has created among organizations, experts, and the society at large. More decisive actions can be taken by the various governing bodies to checkmate the utilization of big data analytics in various organizational levels to tackle these ethical challenges.

\section{REFERENCES}

[1]. Davis, L. (2018). The Unmaking of the President 2016: How FBI Director James Comey Cost Hillary Clinton the Presidency (1st ed., pp. P.57-60). New York: Scribner.

[2]. Ethical Implications Of Big Data Analytics. (n.d.). Retrieved June 25, 2020, from https://docplayer.net/20160908-Ethical-implications-of-big-data-analytics.html

[3]. Hamid Ekbia, Michael Mattioli, Inna Kouper, G. Arave, Ali Ghazinejad, Timothy Bowman, Venkata Ratandeep Suri, Andrew Tsou, Scott Weingart, and Cassidy R. Sugimoto (2015). Big data: Bigger Dilemma.

[4]. Hervais Simo (2016). Big Data: Opportunities and Privacy Concerns, 11 (1).

[5]. Lin, T. (2013, October 3). Big Data is too big for scientists to handle alone. Wired Science. Retrieved from http://www.wired.com/wiredscience/2013/10/big-data-science/

[6]. Low, C. T., Lai, P. C., Yeung, P. S. S., Siu, A. Y. C., Leung, K. T. Y., \& Wong, P. P. Y. (2018). Temperature and age-gender effects on out-of-hospital cardiac arrest cases. Hong Kong Journal of Emergency Medicine, 25(2), 83-90. https://doi.org/10.1177/1024907917751301

[7]. Newell, S., \& Marabelli, M. (2015). Strategic opportunities (and challenges) of algorithmic decision making: A call for action on the long-term societal effects of "datification". Journal of Strategic Information Systems, 24(1), 3-14. 5

[8]. Ohm, P. (2010). Broken promises of privacy: Responding to the surprising failure of anonymization. UCLA Law Review, 57, 1701-1777. 
[9]. Schwartz, P. M., \&Solove, D. J. (2011). The PII problem: Privacy and a new concept of personally identifiable information. New York University Law Review, 86, 1814-1894.

[10]. Solove, D.J. (2013). Introduction: Privacy self-management and the consent dilemma. Harvard Law Review, $126 . \quad$ Retrieved from http://www.harvardlawreview.org/issues/126/may13/Symposium_9475.php

[11]. Someh, I., Davern, M., Breidbach, C., \& Shanks, G. (2019, May 09). Ethical Issues in Big Data Analytics: A Stakeholder Perspective. Retrieved June 25, 2020, from https://paperity.org/p/193498133/ethical-issues-in-big-data-analytics-a-stakeholder-perspective

[12]. Taleb, N. N. (2013, February 8). Beware the big errors of 'Big Data'. Wired. Retrieved from http://www.wired.com/opinion/2013/02/big-data-means-big-errors-people/

[13]. Tam, D. (2012, August 22). Facebook processes more than 500 TB of data daily. CNET. Retrieved from http://news.cnet.com/8301-1023_3-57498531-93/facebook-processes-more-than-500-tb-ofdata-daily/

[14]. Tene, O., \& Polonetsky, J. (2012). Privacy in the age of Big Data: A time for big decisions. Stanford Law Review Online, 64, 63-69.

[15]. Vonett123. (n.d.). On their own to make decisions based upon their own personal reflection: Course Hero. Retrieved June 25, 2020, from https://www.coursehero.com/file/p3lbqsn/on-their-own-tomake-decisions-based-upon-their-own-personal-reflection/ 